\title{
Translation Initiation Factor EIF-2B Subunit Beta
}

National Cancer Institute

\section{Source}

National Cancer Institute. Translation Initiation Factor EIF-2B Subunit Beta. NCI

Thesaurus. Code C38547.

Translation initiation factor elF-2B subunit beta (351 aa, $\sim 39 \mathrm{kDa}$ ) is encoded by the human EIF2B2 gene. This protein is involved in both GDP-GTP exchange and protein synthesis. 